\title{
THE USABILITY OF DIFFERENT SKID RESISTANCE CHARACTERISTICS IN ROAD ASSESSMENT
}

\author{
Matúš KOVÁČ ${ }^{1, *}$, Peter KOTEK ${ }^{1}$ \\ ${ }^{1}$ Department of Highway Engineering, Faculty of Civil Engineering, University of Žilina, Univerzitná \\ 8215/1, 01026 Žilina. \\ * corresponding author: matus.kovac@fstav.uniza.sk, +421-4-1513 5947.
}

\section{Abstract}

The article was created as a reaction on the request of the Slovak Road Administration, whether it would be possible to evaluate level of friction on the road network only by using laser equipped device Profilograph GE, instead of by using longitudinal friction coefficient measuring device Skiddometer BV11, which is slow, much more difficult on operation and it is necessary to fulfil the water tank for measurements. In order to find out the answer, there were evaluated measurements performed on road sections in Slovakia for the past few years. The main goal was to compare results obtained by both devices, and to find a relevant correlation between them. For better understanding of the problematic and for the demonstration of disadvantages of some texture characteristics, there are performed a comparisons of the different parameters evaluated on model surface profiles in the end of this work.
\end{abstract}

\section{Keywords:}

Skid resistance; Friction coefficient; Surface texture; Mean profile depth; Texture characteristics.

\section{Introduction}

Road pavement skid resistance is very important parameter from the pavement serviceability point of view. The skid resistance contributes to the road safety, because its appropriate level directly influences a sufficient interaction between car wheel and the pavement surface. Over the years, there have been developed plenty of methods and devices in order to evaluate the skid resistance. Some of them evaluate the texture of the pavement surface, which directly influences the friction in the first place. The other devices evaluate pavement skid resistance by coefficient of friction, which is defined as a relation of tangential friction power and normal power between a measuring tyre and pavement surface. All these methods differ in principle due to their physical essence, and also the test conditions influencing the results of evaluation are different. In Slovakia, the skid resistance is measured by two devices, which are owned and operated by Slovak road administration. The device Profilograph GE is equipped by 15 lasers, whereas one of them is used for the pavement surface texture evaluation. Results of the measurements performed by Profilograph GE are values of MPD - Mean Profile Depth, which is the surface texture characteristic. Skid resistance measured by the device Skiddometer BV11 provides values of longitudinal friction coefficient $M u$. This parameter shows actually the friction level between wheel and pavement surface, but there are many disadvantages using and operating the device. The repeatability of measurements performed by Skiddometer BV11 is debatable as well, mainly due to plenty of test conditions, which could (and they mostly do) influence the results. That was the reason, why Slovak road administration as an operator wants to replace Skiddometer BV11 measurements with results obtained using Profilograph GE. For that purpose we evaluated eleven long-term monitored road sections, where was measured the skid resistance by both devices. All results were subsequently compared and used for correlation function determination. On the basis of low values of correlation indexes describing the relationship between results gained by different methods, we decided to model some profiles, which would obviously show limitations of the amplitude evaluation of surface texture in term of friction level between wheel and pavement surface. 


\section{Skid resistance - surface texture}

The texture of the surface expresses morphological arrangement of pavement surface material. It creates a basic element of interaction of a vehicle tyre and pavement and is defined by the microtexture of aggregates on the surface and the macrotexture of the pavement surface [1]. In general, the pavement surface texture depends on asphalt mixture composition, especially on aggregate particle size distribution, maximum aggregate size and on type of bitumen binder and its content in the mixture. An example and schematic visual display of micro and macrotexture is shown in the Fig. 1.

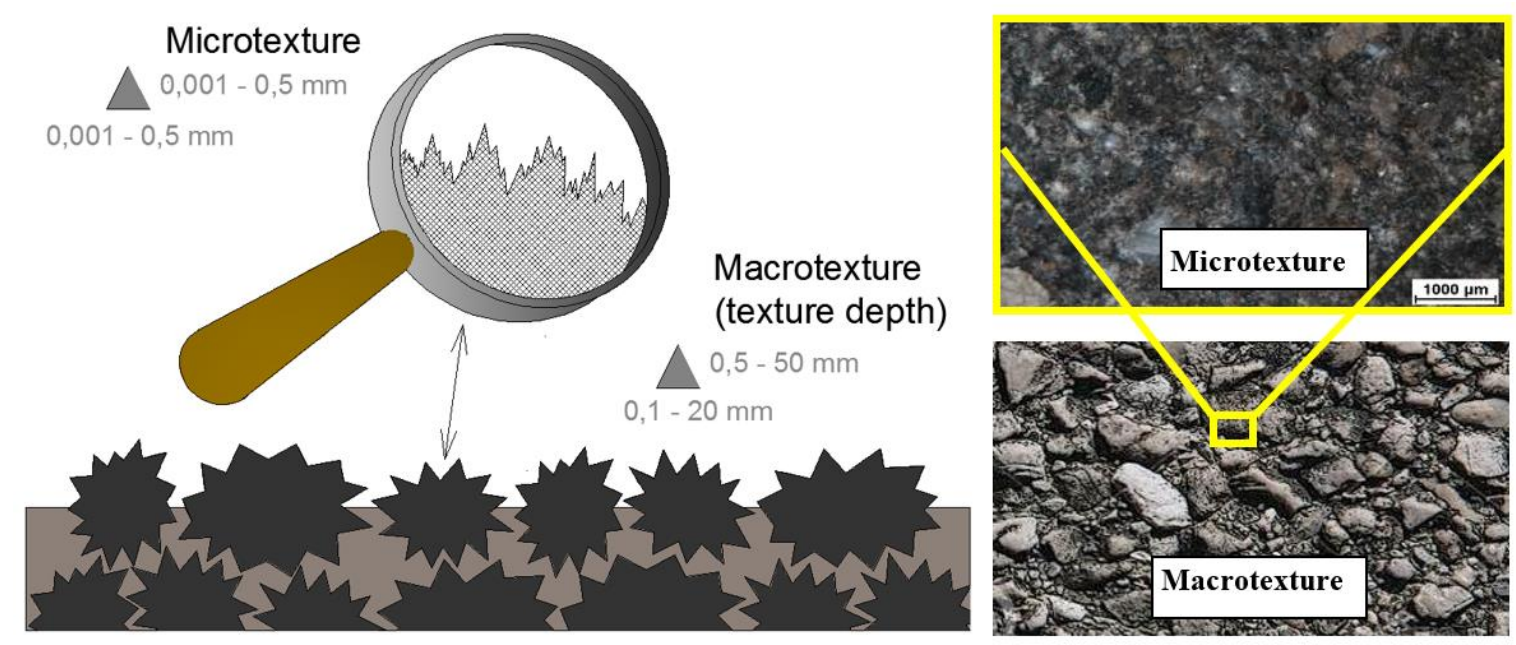

Fig. 1: Texture of pavement surface and differences between macrotexture and microtexture.

Microtexture is created by small prominences of grain aggregates and talks about how the grain aggregates are smooth or rough and therefore contributes to friction between a tyre and pavement surface. It is characterized by the wave length range between 0.001 and $0.5 \mathrm{~mm}$ and the amplitude between 0.001 and $0.5 \mathrm{~mm}$ [2]. It creates an impression of more or less rough surface but usually it is too soft to see it by the naked eye. Micro texture is responsible for basic friction level and is important on dry surface and by small speed up to $40 \mathrm{~km} . \mathrm{h}^{-1}$. It also plays role in interruption of continuous water film and in creation of immediate contact between a vehicle tyre and pavement surface [2]. The micro texture values are partially influenced by ability of aggregates to keep sharp edges. It means to keep the surface so rough in order to resist smoothing caused by traffic especially truck traffic. Micro texture is affected by mineralogical composition of the aggregates, percentage of small aggregates in the asphalt mixture, and content and type of asphalt binder.

Macrotexture of the pavement surface issues basic drainage ability of the pavement. It expresses road irregularities on the pavement surface and describes how single grains are arranged on the pavement surface. It is characterised by wave length range between 0.5 and $50 \mathrm{~mm}$ and amplitude range between 0.1 and $20 \mathrm{~mm}$ [2]. It is important to fast drain off the water from pavement surface. The water acts as lubricant and it influences friction between a tyre and pavement. Macro texture also plays an important role by middle and higher speed over $40 \mathrm{~km} . \mathrm{h}^{-1}$. Good macro texture can be reached when suitable relation of aggregates and mortar of the mixture is designed, and by appropriate method of surface modification can be reached as well.

There are many devices and methods for pavement surface texture evaluation. Most of them evaluate the macrotexture, which is mostly described as an average value of macrotexture depth. For the microtexture evaluation is most commonly used the British pendulum tester, which is an indirect way for estimating of microtexture level. The device Profilograph GE is able to evaluate only macrotexture by the parameter MPD. It is not able to evaluate microtexture of the pavement. 


\section{Skid resistance - coefficient of friction}

The mechanisms of tyre/road friction still haven't been fully understood, but it is widely recognized that there are two main mechanisms involved: molecular adhesion and hysteresis losses, ideas proposed by Kummer in a unified theory of tyre/road friction in the 1960s [3], [4], and developed further by Moore a decade later [5]. The overall friction between tyre and road surface is the sum of these two components. The contribution of adhesion to friction is the sum of the inter-facial shear tension between the tread rubber and the road surface by different islets on the overall contact area, which depend on surface roughness at the microscopic scale. The hysteresis contribution comes from energy losses due to damping in the rubber bulk when this is deformed as it passes over the aggregate particles in the surface. The effects of texture scales on the two basic mechanisms of tyre/road friction can be summarized as the adhesion component being highly sensitive to microtexture, whereas the hysteresis component is mostly sensitive to macrotexture [6].

As mentioned before, for the skid resistance evaluation of the road network, Slovak road administration uses the device Skiddometer BV11. The device allows measurement of the longitudinal coefficient of friction by recording shear resistance using independent measuring wheel pulled on the wet pavement surface with slip ratio of $17 \%$. Output of the equipment is the parameter $M u$ describing longitudinal friction every 2 meters on the road. Measurement technique and evaluation are described in detail in the technical regulation TP14/2006 [7]. The advantage of the device is the direct evaluation of the friction value between wheel and wet pavement surface, which means that there are evaluated both elements of the texture, the micro texture and the macro texture. The disadvantages of the device is difficult operating and plenty of test conditions which influence the measured value of the friction coefficient, such as measuring speed, temperature, tyre (type, normal load, tread depth, pressure), and the season in which is the measurement performed. It is much more complicated to eliminate these influences as it is by measuring with laser based device.

\section{Skid resistance evaluation}

As mentioned before, the skid resistance is possible to evaluate by coefficient of friction or by evaluating the surface texture.

In pavement management system, there is for the texture evaluation used the MPD parameter, but there are many other different kinds of parameters for surface texture evaluation, such as the height (amplitude) parameters $\left(R_{a}, R_{q}\right)$, the height distribution shape parameters $\left(R_{s k}, R_{k u}\right)$, wavelength parameters $(P S D)$, or hybrid parameters $(T R)$. For the comparison with friction coefficient $M u$, there was computed the MPD parameter and for determination of the usability of different texture characteristics, there were additionally computed parameters: $R_{a}, R_{q}, R_{s k}, R_{k u}$, and TR.

The $R_{a}$ (Arithmetical mean deviation) and $R_{q}$ (Root means square deviation) parameters characterise an absolute measure of the surface texture and are defined by equations (1) and (2) as following:

$$
\begin{aligned}
& R_{a}=\frac{1}{n} \sum_{i-1}^{n}|y-\bar{y}|,(\mathrm{mm}) \\
& R_{q}=\sqrt{\frac{1}{n} \sum_{i=1}^{n}\left(y_{i}-\bar{y}\right)^{2}} \cdot(\mathrm{mm})
\end{aligned}
$$

Unfortunately, these parameters aren't able to distinguish between peaks, valleys and the spacing between them, which means that, for example, two very different surfaces in term of skid resistance can be described by the same value $R_{a}$. That's why it is important to evaluate also parameters such as $R_{s k}, R_{k u}$ or $P S D$ respectively.

The $R_{s k}$ parameter (Skewness) describes the symmetry of the heights about the mean plane, and allows defining so called "positive" and "negative" surface texture, which is very important in term of the influence on friction or noise emissions production. The $R_{s k}$ parameter is computed according to equation (3) as follows:

$R_{s k}=\frac{\sum_{i=1}^{n}\left(y_{i}-\bar{y}\right)^{3}}{n \cdot \sigma^{3}}$. 
The $R_{k u}$ parameter (Kurtosis of profile) indicates the presence of disproportionately high peaks or deep valleys, and is important for defining a wear conditions. The $R_{k u}$ parameter is computed according to equation (4) as follows:

$R_{k u}=\frac{\sum_{i=1}^{n}\left(y_{i}-\bar{y}\right)^{4}}{n . \sigma^{4}}-3$,

where: $y_{i} \quad$ is height of the surface profile at point $\mathrm{i}$;

$\bar{y} \quad$ is the average of all profile heights;

$\sigma \quad$ is the standard deviation of the profile.

The MPD parameter is the Mean Profile Depth and it is calculated as a difference of the average value of the two peaks at every half profile on certain distance and the average value of all heights of the profile. The MPD value is computed according to equation (5) as follows:

$M P D=\frac{\left(M_{1}-M_{2}\right)}{2}-\bar{y} \cdot(\mathrm{mm})$

The TR parameter (Texture Ratio) is a hybrid parameter computed as a ratio of MPD value to $R_{q}$ in order to better describe the pavement skid resistance.

$T R=\frac{M P D}{R_{q}}$.

Wavelength analysis of all surfaces wasn't evaluated yet.

\section{Data analysis}

For the purpose of comparison and to confirm or disprove the ability to replace the Skiddometer BV11 with the Profilograph GE, there were evaluated the Mu and MPD parameters, which were measured on 16 road sections. The example of six road sections with evaluated parameters and values describing their measure of their correlation are showed in the Table 1. All measured values were compared at the interval of every second meter (Fig. 2) and compared to each other (Fig. 3). Given that the results of comparison showed very low level of correlation, which could be caused by incorrect measurements conformity, were subsequently computed average values of both parameters for whole road section. The comparison of all results is showed in the Fig. 4.

Table 1: The example of six sections with results of evaluation.

\begin{tabular}{|c|c|c|c|c|c|}
\hline $\begin{array}{c}\text { Name of the road } \\
\text { section [-] }\end{array}$ & File name [-] & $\mathbf{M u}[-]$ & $\begin{array}{c}\text { MPD } \\
{[\mathbf{m m}]}\end{array}$ & $\begin{array}{c}\text { Correlation } \\
\text { coefficient R [-] }\end{array}$ & $\begin{array}{c}\text { Confidence } \\
\text { coefficient } \\
\mathbf{R}^{2}[-]\end{array}$ \\
\hline \multirow{2}{*}{ Budimír I/68 - S/KE } & $\mathrm{S} 1129$ & 72 & & 0.1329 & 0.0177 \\
\cline { 2 - 6 } & $\mathrm{P} 47200703060016$ & & 1.22 & 0.0870 & 0.0076 \\
\hline \multirow{2}{*}{ Gánovce I/18 - KE } & $\mathrm{S} 1101$ & 65 & & -0.0041 & 0.0000 \\
\cline { 2 - 6 } & $\mathrm{P} 47200703060010$ & & 0.89 & -0.0042 & 0.0000 \\
\hline \multirow{2}{*}{ Sliač I/66 (R1) - ZV } & $\mathrm{S} 1319$ & 72 & & 0.1771 & 0.0314 \\
\cline { 2 - 6 } & $\mathrm{P} 47200703270011$ & & 0.97 & 0.1711 & 0.0293 \\
\hline \multirow{2}{*}{ Brodno I/11 - ZA } & $\mathrm{S} 1116$ & 46 & & 0.3602 & 0.1297 \\
\cline { 2 - 6 } & $\mathrm{P} 47200703050010$ & & 0.60 & 0.4311 & 0.1859 \\
\hline \multirow{2}{*}{ Žilina-STK I/18 - ZA } & $\mathrm{S} 1209$ & 54 & & 0.5697 & 0.3245 \\
\cline { 2 - 6 } & $\mathrm{P} 47200703050013$ & & 0.69 & 0.3608 & 0.1302 \\
\hline \multirow{2}{*}{ Sl. Skaly I/64 - ZA } & $\mathrm{S} 1143$ & 38 & & 0.5874 & 0.3450 \\
\cline { 2 - 6 } & $\mathrm{P} 47200703050016$ & & 0.45 & 0.3352 & 0.1123 \\
\hline
\end{tabular}




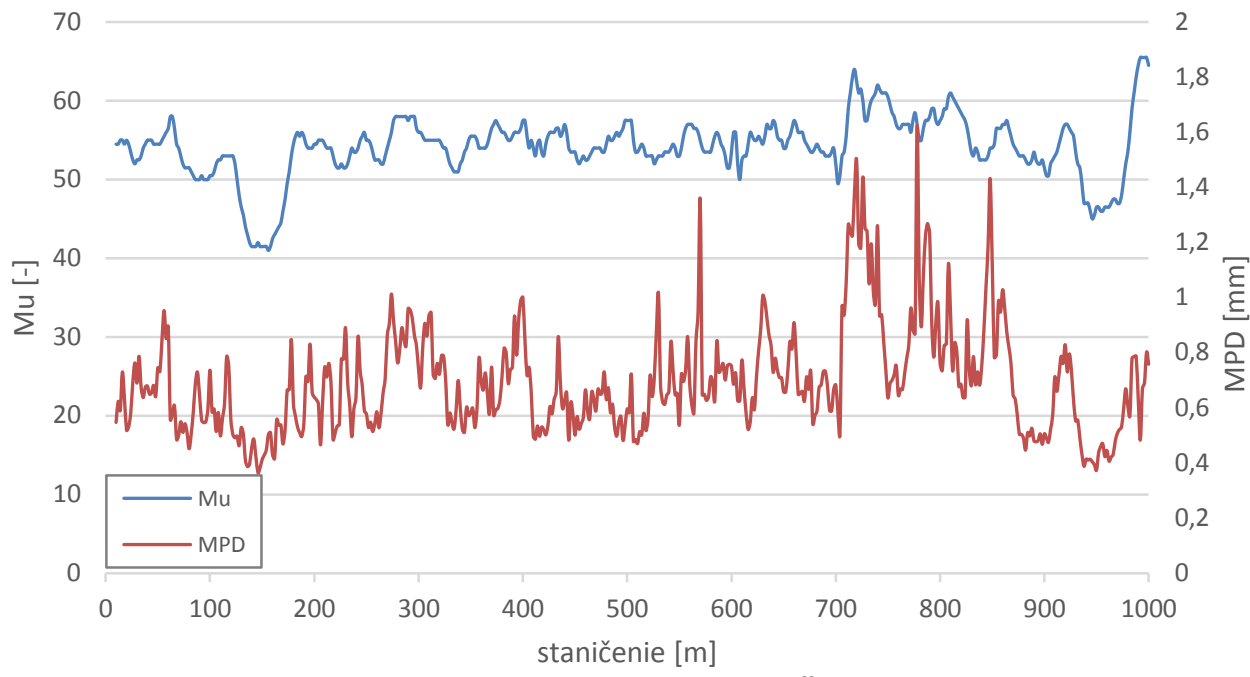

Fig. 2: MPD and Mu values on road section Žilina - STK I/18 - ZA.

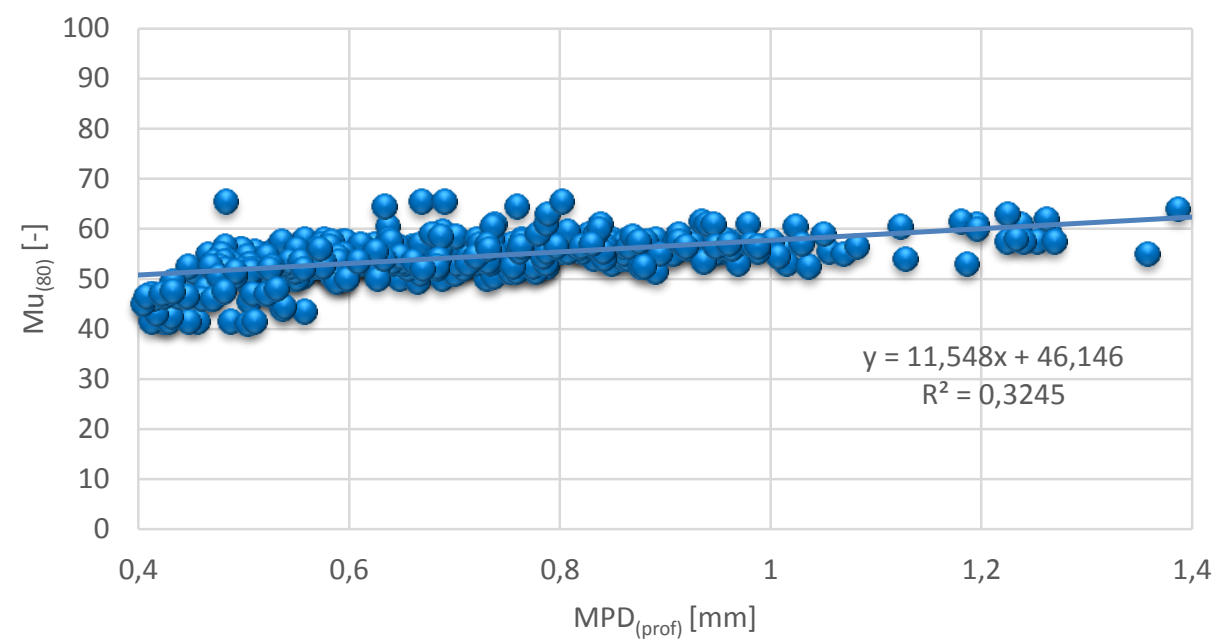

Fig. 3. The correlation between $M u$ and $M P D$ values compared every second meter on road section Žilina - STK I/18 - ZA.

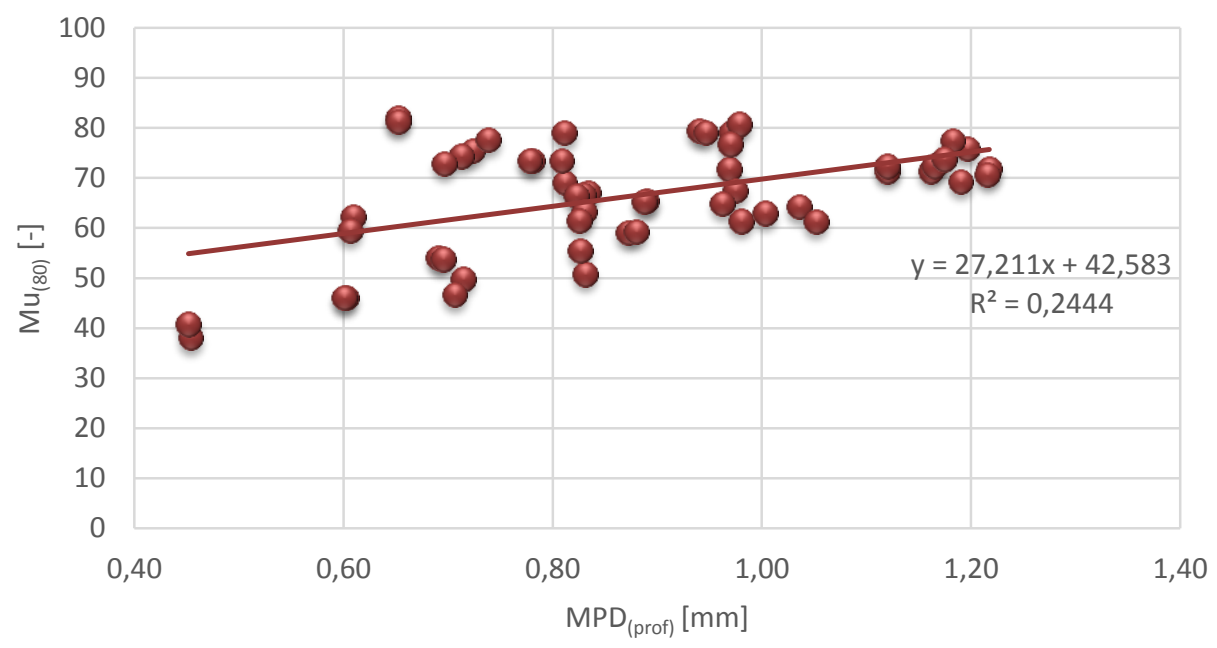

Fig. 4: The correlation between average Mu and MPD values on all monitored sections. 
As it can be seen in the Fig. 4, there is no relevant correlation between $M u$ and MPD parameters. The reason why it is happening is because the $M u$ value describes the friction value between wheel and pavement surface, inclusive both micro and macro texture, while the MPD parameter is able to describe only macro texture and also this is described just as an average value of the macrotexture profile depth. To support this finding, and for better understanding of the issue, there were performed comparisons on model surface profiles.

\section{Model surface profiles}

For better understanding of the problematic of the describing surface profiles in term of friction level between a car wheel and a road pavement surface, and for demonstration of disadvantages of some texture characteristics, authors decided to create simplified model examples of the surface profile, and perform comparisons of the different texture characteristics. The profiles (Fig. 5) were created in order to represent pavement surfaces with evidently good and bad conditions from the level of skid resistance point of view. The measures of the profiles are not supposed to be taken into account, the important part is that the profiles should suggest a slippery, or rough pavement surface. There were created 24 different model profiles. As an example are presented six of them, on which the calculations of above mentioned texture characteristics were performed.
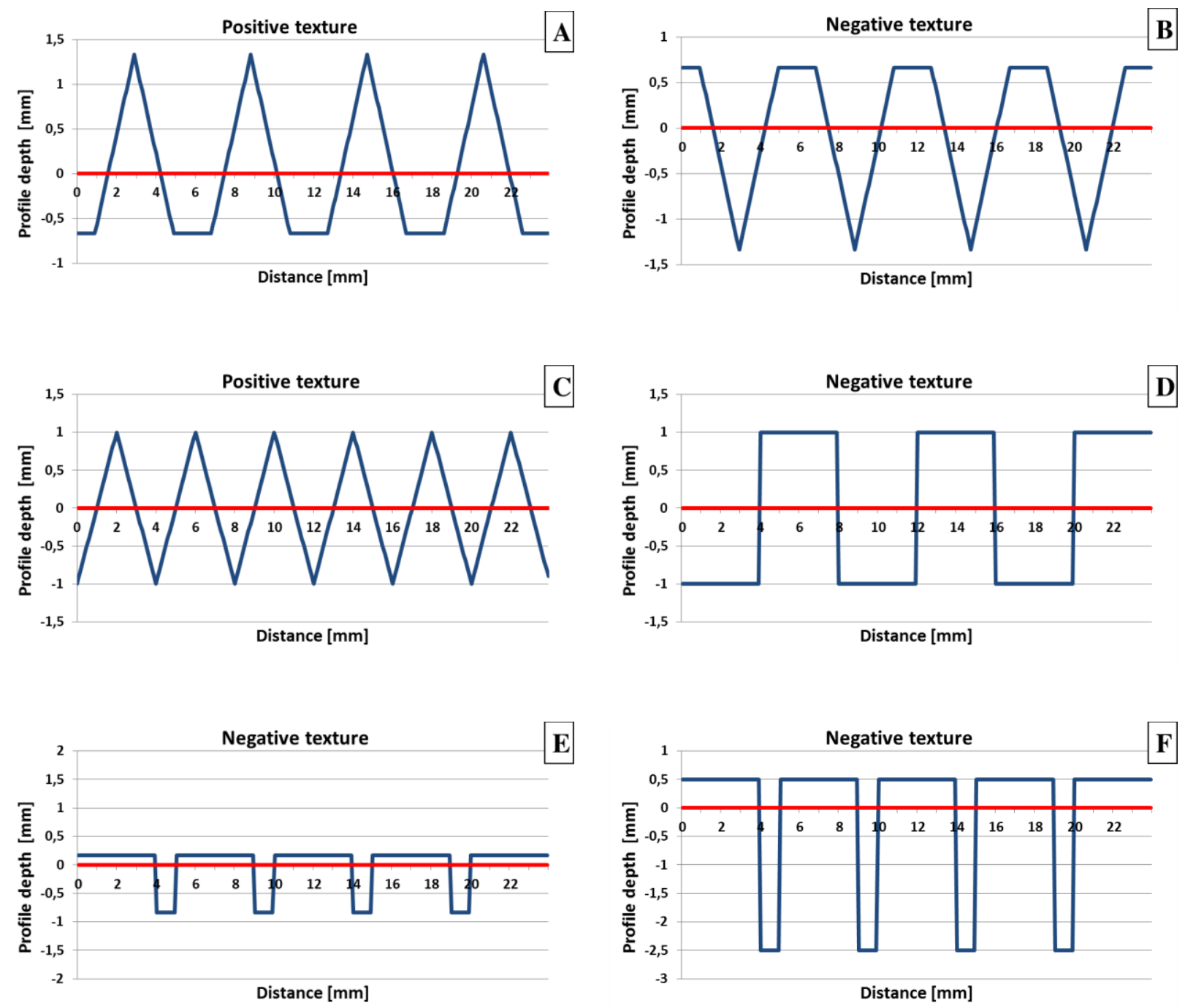

Fig.5: Different types of simplified profiles of the pavement surface texture. 
The computed texture characteristics (MPD, $\left.R_{a}, R_{q}, T R, R_{s k}, R_{k u}\right)$ for model profiles are listed in the Table 2.

Table 2: The computed texture characteristics for model profiles.

\begin{tabular}{|c|c|c|c|c|c|c|}
\hline Profile & $\boldsymbol{M P D}$ & $\boldsymbol{R}_{\boldsymbol{a}}$ & $\boldsymbol{R}_{\boldsymbol{q}}$ & $\boldsymbol{T R}$ & $\boldsymbol{R}_{\boldsymbol{s k}}$ & $\boldsymbol{R}_{\boldsymbol{k} \boldsymbol{u}}$ \\
\hline A & 1.33 & 0.000 & 0.667 & 1.998 & 0.502 & -1.194 \\
\hline B & 0.67 & 0.000 & 0.667 & 0.999 & -0.502 & -1.194 \\
\hline C & 1.00 & 0.000 & 0.579 & 1.728 & 0.000 & -1.188 \\
\hline D & 1.00 & 0.000 & 1.000 & 1.000 & 0.000 & -2.017 \\
\hline E & 0.17 & 0.000 & 0.373 & 0.447 & -1.789 & 1.251 \\
\hline F & 0.50 & 0.000 & 1.118 & 0.447 & -1.789 & 1.251 \\
\hline
\end{tabular}

The analysis of the results shows that the MPD parameter not always correctly interprets the skid resistance of the surface, because as it is given by the way the parameter is computed, there is not possibility to consider the shape and distribution of the surface irregularities. For example, at $\mathrm{E}$ and $\mathrm{F}$ profiles, which would have obviously the same influence on friction level between the rubber wheel and the surface, the MPD values are markedly different. On the other hand, the same MPD value at profiles $C$ and $D$ describes two clearly different profiles considering the ability to provide a proper amount of skid resistance level. As far as the $R_{a}$ characteristic concerned all profiles shows the zero value, because all profiles are symmetric about the axis $x$ and the average value of the profile heights is zero. The $R_{q}$ characteristic also doesn't describe correctly the profiles in the terms of surface skid resistance, but is very useful for determination the hybrid $T R$ parameter. The $R_{s k}$ and $R_{k u}$ parameters correctly described the negative and positive texture, or the distribution of valleys and peaks above and below the mean line, but at real surfaces we don't consider it as very helpful. On the contrary, considering results on all evaluated model profiles, we can tell that the texture ratio $(T R)$ is the best easy available characteristic for describing the friction level between wheel and pavement based on measurements by laser device. As we can see, obviously slippery profiles are described with the smallest values, and the rough surfaces are described with the biggest values. On the other hand, the $E$ and $F$ profiles, which have the same fictitious contact area between wheel and pavement surface, are described with the same TR value irrespective of valleys depth (MPD differences).

Of course, none of these parameters consider the wavelength of the irregularities of the surface, which is also very important parameter for comprehensive description of the shape of the texture. And also it needs to be mentioned, that currently there are not such laser devices which could measure the pavement surface at the microtexture level.

All these results confirmed the statement reached on the real road sections, that the MPD parameter is not able to objectively evaluate the road pavement skid resistance, so the Skiddometer BV11 can't be replaced with Profilograph GE. Also the conversion equations between these and also other parameters don't make any sense.

\section{Conclusions}

The article deals with the question, if it is possible to replace the Skiddometer BV11 with laser based device Profilograph GE due to better operating conditions. For the purpose of the decision, there were evaluated measurements performed by both devices on 16 road sections and $M u$ and MPD parameters were compared. The result of the comparison was that there isn't any relevant correlation between these two parameters. For better understanding of the problematic of the describing surface profiles in the terms of friction level between a car wheel and a road pavement surface, and for demonstration of disadvantages of some texture characteristics, there were created simplified model examples of the surface profiles, and performed comparisons of the different texture characteristics. All gained results confirmed the statement reached on the real road sections that the MPD parameter is not able to objectively evaluate the road pavement in the terms of skid resistance, and also that the texture ratio $(T R)$ is the best easy available characteristic for describing the friction level between wheel and pavement based on measurements by laser device. However, for 
comprehensive evaluation of the pavement skid resistance by laser scanning, it will be necessary to evaluate the wavelength of the irregularities of the surface as well. Also it will be inevitable to increase the scanning resolution in order to record the micro texture of the pavement surface, which is the very important part for an objective evaluation of the friction level between a car wheel and the road pavement.

\section{Acknowledgent}

This paper was worked in as a part of solution of the project VEGA 1/0804/12 "The influence of material composition of asphalt mixtures on characteristics of surface texture and emission."

\section{References}

[1] KOVÁČ, M. et al.: Diagnostika parametrov prevádzkovej spôsobilosti vozoviek, EDIS Žilina 2012. ISBN 978-80-554-0568-1.

[2] STN EN ISO 13473-5, Charakterizovanie textúry vozovky s použitím profilov povrchu. Čast' 5: Stanovenie megatextúry (ISO 13474-5:2009).

[3] KUMMER, H. W.: Unified theory of rubber and tire friction, Engineering Research Bulletin B-94, Pennsylvania State University College of Engineering, Pennsylvania, 1996.

[4] KUMMER, H. W. - MEYER, W. E.: Unified theory of rubber friction reveals adhesion component's role in the tire-road surface coupling, SAE Journal, volume 75 number 8, pages 70-73, 1967.

[5] MOORE, D. F.: Principles and Applications of Tribology, Perg. Inter. Libr., Vol. 14, P-388, 1975.

[6] TYROSAFE - Tyre and Road Surface Optimisation for Skid Resistance and Further Effects. Coordination Action FP7-217920 Seventh Framework Programme, Theme 7: Transport. D10. Report on different parameters influencing skid resistance, rolling resistance and noise emissions. This project is part of the FEHRL Strategic Research Programme "SERRP IV" (www.fehrl.org).

[7] TP14/2006, Meranie a hodnotenie drsnosti vozoviek pomocou zariadením SKIDDOMETER BV11 a PROFILOGRAPH GE. 